Research Article

\title{
Investigation of the Effects of Evaporation Methods on the High-Temperature Rheological and Fatigue Performances of Emulsified Asphalt Residues
}

\author{
Yang Sun, ${ }^{1}$ Jin-Chao Yue $\mathbb{D}^{1},{ }^{1}$ Ri-Ran Wang, ${ }^{1}$ Rui-Xia Li, ${ }^{1}$ and De-Cai Wang $\mathbb{D}^{1,2}$ \\ ${ }^{1}$ School of Water Conservancy Engineering, Zhengzhou University, Zhengzhou 450001, China \\ ${ }^{2}$ School of Civil Engineering and Communication, North China University of Water Resources and Electric Power, \\ Zhengzhou 450045, China
}

Correspondence should be addressed to De-Cai Wang; decaiww@sina.com

Received 8 November 2019; Revised 26 January 2020; Accepted 15 February 2020; Published 16 March 2020

Guest Editor: Andrea Graziani

Copyright (c) 2020 Yang Sun et al. This is an open access article distributed under the Creative Commons Attribution License, which permits unrestricted use, distribution, and reproduction in any medium, provided the original work is properly cited.

Cold recycling technology is a widely applied asphalt pavement rehabilitation technology. The properties of emulsified asphalt residues after water evaporates play an important role in the performance of the asphalt pavement. This paper investigates the rheological and fatigue properties of emulsified asphalt residues under different evaporation methods. Two different matrix asphalt binders and emulsifiers were selected to prepare the emulsified asphalt. Moreover, the direct heating method (DHM) and the EN13074 and ASTM D7497-09 evaporation methods were used to obtain emulsified asphalt residues. Furthermore, the linear viscoelasticity, the permanent deformation resistance, and the fatigue resistance were evaluated by the temperature sweep and frequency sweep tests, the multiple stress creep recovery (MSCR) test, and the linear amplitude sweep (LAS) test, respectively. The test results show that under the three evaporation conditions, the growth amplitude order of the rutting factor, recovery percent, complex modulus, and fatigue life of emulsified asphalt residues is ASTM D7497-09 > EN13074 > DHM, and as is the attenuation amplitude order of the nonrecoverable creep compliance and phase angle. The results reveal that the evaporation process leads to oxidation and hardening of the residues. The hardening degree of the ASTM D7497-09 evaporation method is higher than that of the EN13074 evaporation method, and the hardening degree of the EN13074 evaporation method is higher than that of the direct heating method. The rheological and fatigue performances of the emulsified asphalt residues depend on the matrix asphalt. Moreover, the residue that was prepared from 70\# asphalt has good high-temperature and fatigue properties, but it has higher temperature sensitivity and stress sensitivity.

\section{Introduction}

Cold recycled mixture of emulsified asphalt has become one of the most popular approaches for asphalt pavement maintenance, rehabilitation, and reinforcement, with the advantage of excellent pavement performance, resource conservation, and environmental friendliness [1-4]. Studies have found that the asphalt emulsion has a substantial influence on the rheological characteristics and the mechanical properties of the cold recycled mixture [5, 6]. Moreover, the performance of emulsified asphalt mainly depends on the technical properties of residues after the moisture is evaporated. The emulsified asphalt residue is used as a key specification and quality control parameter for the emulsified asphalt [7], and also its performance is related to the characteristics during the service period. Therefore, it is necessary to recover residues and investigate their properties.

Similar to asphalt binders, emulsified asphalt residue is a viscoelastic plastic material. Rheological measurement has been proven to be a favorable approach for optimizing the recovery methods of emulsified asphalt residue [8-10]. Common residue recovery methods include distillation, evaporation, moisture analyzer balance (MAB) [11], and the SAFT (stirred air flow test with nitrogen) method [12]. Distillation methods, such as ASTM D6997 and ASTM D7403, are more scientific methods of residue collection and 
are more widely used to recover emulsion residue $[13,14]$. However, the distillation method easily causes aging and even damage to the microscopic structure of emulsified asphalt residue due to its high-temperature [15]. Thus, the residue obtained by distillation method will not have the same properties as that obtained in the field [5, 16-18]. Evaporation methods mainly include the vacuum drying method, the air blowing evaporation method, the lowtemperature evaporation drying method, and other methods. Islam et al. [19] prepared emulsified asphalt residue by the vacuum drying method and studied the effects of variables including the curing time, temperatures, and vacuum pressure on the rheological properties of the recovered asphalt emulsion residue. The direct heating method is mainly used in China and Japan, and the proficiency levels of operators substantially impact the experimental results $[20,21]$. Gao and Pang [22] obtained emulsified asphalt residue by the direct heating method and established the relationships between rheological parameters and road performance indexes by interfacial rheology and dynamic shear rheology. The low-temperature evaporation method is favored by researchers because the evaporation temperature is closer to the application temperature of emulsified asphalt. Hanz et al. [17] used the ASTM D7497-09 evaporation method to obtain emulsified asphalt residue and carried out rheological tests on the residues with different curing times. $\mathrm{Xu}$ et al. [9] used the recovery method that was proposed by the EN13074 method (including both the recovery and stabilization processes at moderate temperatures) to obtain the residue, and the corresponding matrix asphalt binders were treated via the same method for comparison.

However, the properties of the residues obtained by different evaporation methods are different. Some researchers compared and analyzed the influence of different evaporation methods on the performance of emulsified asphalt residues. Malladi et al. [23] compared the vacuum drying procedure with the AASHTO PP72 procedure and found that the vacuum-dried residues were softer and more viscous than the residues recovered by the AASHTO PP72 procedure. Marasteanu and Clyne [5] used air-curing and RTFOT-curing to recover the residue and evaluated the lowand high-temperature performances of the residues. The results indicated that the residues cured by RTFOT were stiffer, especially the polymer modified residues.

In summary, the research on emulsified asphalt residues mainly focuses on the residue acquisition method and rheological performance and rarely involves the influence of the evaporation method on the residue performance. Although the evaporation temperature of the low-temperature evaporation method is lower, the evaporation time is longer. Compared with other methods to obtain emulsified asphalt residue, whether it will affect the performance of emulsified asphalt residue needs further research. Moreover, there are few studies on the fatigue properties of emulsified asphalt residues, and the fatigue resistance of the asphalt binder significantly affects the overall fatigue performances of asphalt mixtures [24]. Therefore, based on laboratory experiments, the effect of evaporation method on the hightemperature performance and fatigue performance of emulsified asphalt residues is systematically studied, and the characteristics of cold recycled emulsified asphalt material properties are accurately characterized, thus guiding engineering practice.

\section{Materials and Testing Methods}

2.1. Materials. 70\# asphalt was supplied by Guangraokelida Petrochemical Technology Co., Ltd., Shandong, China, and 90\# asphalt was supplied by SK Co., Ltd., Korea. Emulsifiers KZW-803L and Redicote E-4875 were produced by Kangzewei Technology Co., Ltd., Tianjin, China, and Akzo Nobel Co., Ltd., Shanghai, China, respectively. Two emulsifiers are brown liquid and easily soluble in water. The solid content of KZW-803L emulsifier is more than $50 \%$, and the solid content of Redicote E-4875 emulsifier is $48-53 \%$. Technical information about the asphalt binders and emulsifiers is presented in Tables 1 and 2, respectively. A colloidal mill of the model RINKMD-1, which was fabricated in Germany, was used to prepare the emulsified asphalt. The preparation process of the emulsified asphalt is presented in Figure 1 [25]. The prepared emulsified asphalt was referred to as $\mathrm{K}$ and E emulsified asphalt.

\subsection{Testing Methods}

2.2.1. Recovery of the Emulsified Asphalt Residue. Direct heating method [20] and EN13074 and ASTM D7497-09 (Method A) evaporation methods [16] were selected to prepare emulsified asphalt residues. Figure 2 shows the process of obtaining the emulsified asphalt residues by the evaporation method of EN13074 and ASTM D7497-09 (Method A).

The weights of the recovered residues and the original emulsified asphalt were recorded and used to calculate the water loss percentage of emulsified asphalt. The water loss rate result is presented in Figure 3. More than $86 \%$ of the water was evaporated in the first stage. After 42 hours, the water loss rate minimally increased, and the emulsified asphalt residues still contained small amounts of water after 48 hours. Mitchell et al. [26] used size exclusion chromatography (SEC) to assess the presence of residual water and determined that the residue that was obtained by the lowtemperature evaporation method contained water. However, the presence of residual water in the residues that were obtained by the ASTM D7497-09 and EN13074 evaporation methods does not affect the rheological properties of the residues $[19,23]$. Under the same evaporation conditions, the water loss rate of emulsified asphalt is related to the type of emulsifier. Moreover, the water loss rate of emulsified asphalt under the EN13074 evaporation method is less than that under the ASTM D7497-09 evaporation method. The same change trend is observed for the 90\# emulsified asphalt.

2.2.2. Physical Performance Tests. Physical tests of the penetration, softening point, and ductility were conducted in accordance with ASTM D5, ASTM D36, and ASTM D113 [27-29], respectively. The penetration test temperature was 
Table 1: Properties of the 70\# and 90\# matrix asphalt binders.

\begin{tabular}{lcc}
\hline Technical parameters & & Values \\
& $70 \#$ & SK 90\# \\
\hline Penetration at $25^{\circ} \mathrm{C},(0.1 \mathrm{~mm})$ & 72.0 & 91.2 \\
Softening point $\left({ }^{\circ} \mathrm{C}\right)$ & 48.8 & 46 \\
Ductility at $15^{\circ} \mathrm{C}(\mathrm{cm})$ & $>150$ & $>150$ \\
Viscosity at $135^{\circ} \mathrm{C}($ Pa.s $)$ & 0.65 & 0.51 \\
\hline
\end{tabular}

TABLE 2: Technical information on the emulsifiers.

\begin{tabular}{lccccc}
\hline Emulsifier type & Ion type & Demulsification speed & Emulsifier content (\%) & Optimum bitumen content (\%) & pH requirement \\
\hline KZW-803L & Cationic & Slow-breaking & 3 & 62 & $2.0-2.5$ \\
Redicote E-4875 & Cationic & Slow-breaking & 2 & 63 & $2.0-3.0$ \\
\hline
\end{tabular}

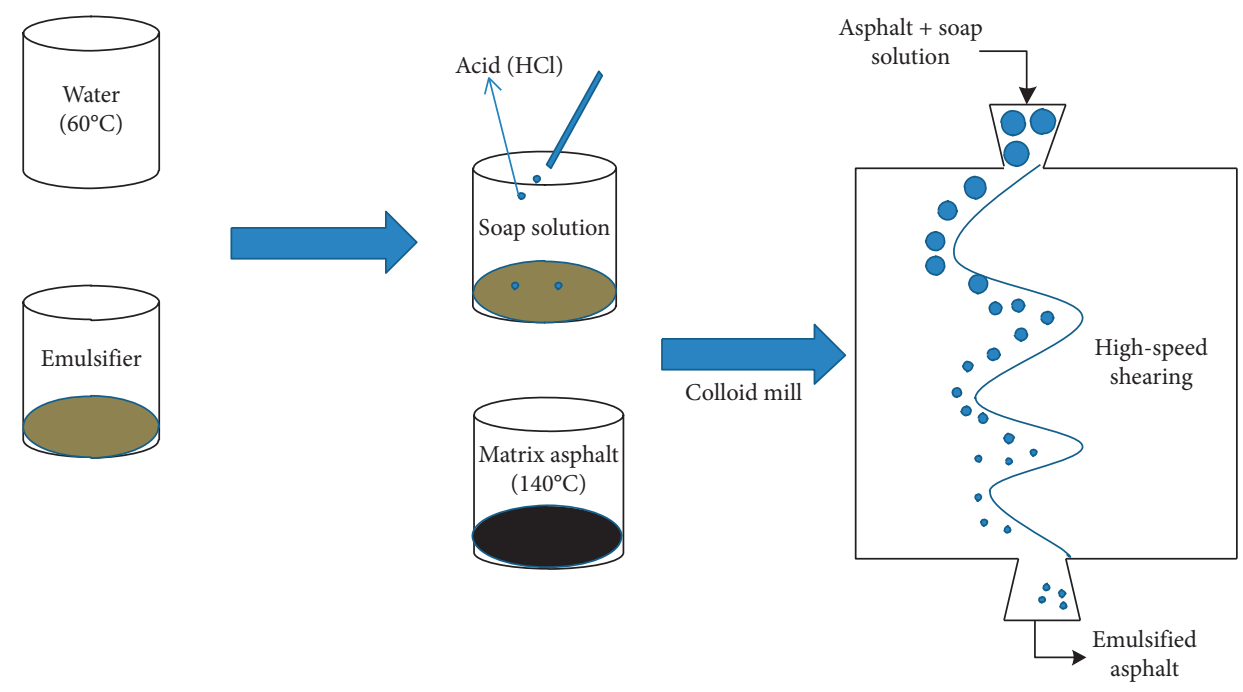

FIgURE 1: Preparation of the emulsified asphalt.

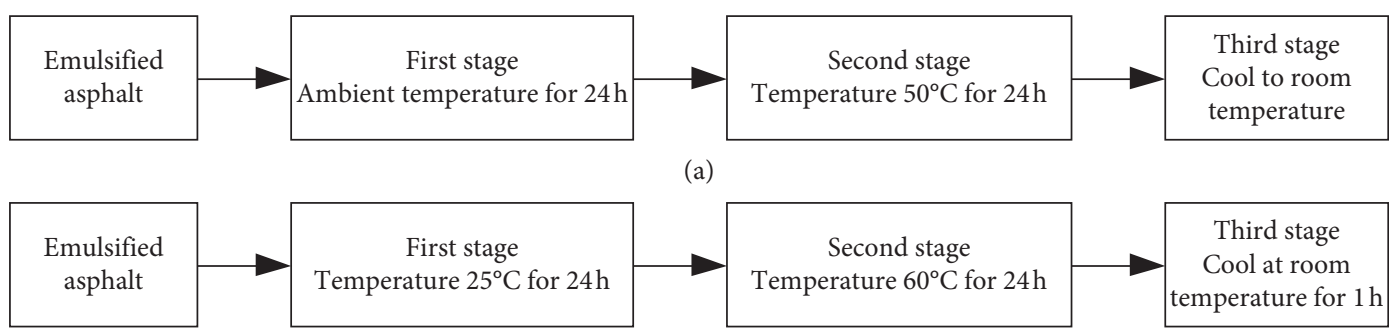

(b)

FIGURE 2: Recovery procedure of emulsified asphalt residues, (a) recovery procedure of emulsified asphalt residues according to EN13074, (b) recovery procedure of emulsified asphalt residues according to ASTM D7497-09.

$25^{\circ} \mathrm{C}$, and the temperature for the ductility test was $15^{\circ} \mathrm{C}$. Three samples were prepared to ensure the repeatability of the tests, and the average of three results was finally obtained.

2.2.3. Temperature Sweep Test. A DHR-1 hybrid rheometer (TA Instrument, New Castle, Delaware) was utilized to test the rheological and fatigue properties of the emulsified asphalt residues. The test temperature started at $58^{\circ} \mathrm{C}$ and increased to $82^{\circ} \mathrm{C}$ in $6^{\circ} \mathrm{C}$ intervals. The strain level was $12 \%$, and the testing frequency was $10 \mathrm{rad} / \mathrm{s}$ [30]. The parallel plate geometry of $25 \mathrm{~mm}$ diameter and $1 \mathrm{~mm}$ gap was applied.

2.2.4. Frequency Sweep Test. The controlled strain of the frequency sweep test was maintained at $0.1 \%$ to ensure that the rheological behaviors of residues were in the linear 


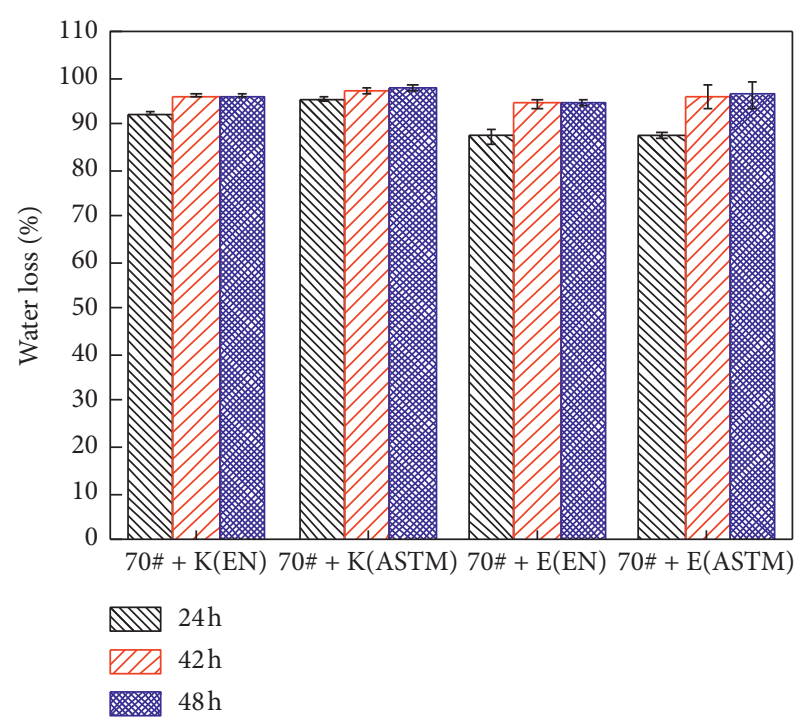

FIgURE 3: Loss percentage of the water content of the emulsified asphalt.

viscoelastic range. The test angular frequencies ranged from $0.1 \mathrm{rad} / \mathrm{s}$ to $10 \mathrm{rad} / \mathrm{s}$, and test temperatures were $20^{\circ} \mathrm{C}, 30^{\circ} \mathrm{C}$, $40^{\circ} \mathrm{C}, 50^{\circ} \mathrm{C}$, and $60^{\circ} \mathrm{C}$. A parallel plate of $25 \mathrm{~mm}$ in diameter with a $1 \mathrm{~mm}$ gap was used when the testing temperature exceeded $30^{\circ} \mathrm{C}$, whereas the parallel plate of $8 \mathrm{~mm}$ in diameter with a $2 \mathrm{~mm}$ gap was used when the testing temperature below $30^{\circ} \mathrm{C}$.

The Christenson-Anderson-Marasteanu (CAM) model was used to fit the complex modulus and the phase angle master curves to provide the undamaged material responses [31]. The time-temperature shift factor was fitted with the Williams-Landel-Ferry (WLF) nonlinear function as expressed in equation (1) [32]. The reference temperature of the complex modulus and phase angle main curve was $40^{\circ} \mathrm{C}$ :

$$
\lg \alpha_{t}=\frac{-C_{1}\left(T-T_{0}\right)}{C_{2}+\left(T-T_{0}\right)},
$$

where $T_{0}$ and $T$ represent the reference temperature and the actual temperature, respectively, and $C_{1}$ and $C_{2}$ are the fitting parameters.

2.2.5. Multiple Stress Creep Recovery (MSCR) Test. The MSCR test can more accurately evaluate the high-temperature performance of the asphalt binder $[33,34]$. The MSCR test adopted the parallel plate geometry of $25 \mathrm{~mm}$ diameter and $1 \mathrm{~mm}$ gap, and the test temperatures were $64^{\circ} \mathrm{C}$ and $70^{\circ} \mathrm{C}$. The emulsified asphalt residue was subjected to 10 cycles of 1 second creep and 9 seconds recovery at a stress level of $0.1 \mathrm{kPa}$, followed by another 10 cycles of creep and recovery at $3.2 \mathrm{kPa}$. The performance indicators consist of the nonrecoverable compliance $\left(J_{\mathrm{nr}}\right)$ and the recovery percent $(R)$, which can be calculated using equations (2) and (3), respectively. The stress sensitivity $J_{\mathrm{nr}}$, diff is the difference between the $\mathrm{J}_{\mathrm{nr}}$ values at the stress levels of $3.2 \mathrm{kPa}$ and $0.1 \mathrm{kPa}$, as expressed in equation (4).

$$
\begin{aligned}
J_{\mathrm{nr}} & =\frac{\gamma_{u}}{\tau} . \\
R & =\frac{\gamma_{p}-\gamma_{u}}{\gamma_{p}-\gamma_{0}} \times 100 \% . \\
J_{\mathrm{nr}, \text { diff }} & =\left[\frac{J_{\mathrm{nr} 3.2}-J_{\mathrm{nr} 0.1}}{J_{\mathrm{nr} 0.1}}\right] \times 100 \%,
\end{aligned}
$$

where $\gamma_{p}$ is the peak strain after a one-second creep duration; $\gamma_{0}$ is the shear strain at the beginning of the cycle; $\gamma_{u}$ is the nonrecoverable strain after a nine-second recovery; and $\tau$ is the creep stress.

2.2.6. Linear Amplitude Sweep (LAS) Test. The LAS test was developed as an accelerated fatigue procedure for evaluating the damage resistance of asphalt binders $[35,36]$. The LAS procedure consisted of two steps [37]. First, the frequency sweep was performed from 0.2 to $30 \mathrm{~Hz}$ at a strain level of $0.1 \%$, which was in the linear viscoelastic behavior range. This step was used to obtain the undamaged material property $(\alpha)$. Then, the emulsified asphalt residues were conducted under an oscillatory strain sweep at a constant frequency of $10 \mathrm{~Hz}$ with amplitudes that ranged linearly from $0.1 \%$ to $30 \%$. The data of this step were used to calculate the damage property via viscoelastic continuum damage (VECD) mechanics analysis. The LAS testing temperature was $25^{\circ} \mathrm{C}$. The damage accumulation in the emulsified asphalt residue is calculated using equation (5):

$$
\begin{aligned}
D(t) \cong & \sum_{i=1}^{N}\left[\pi I_{D} \gamma_{0}^{2}\left(\left|G^{*}\right| \sin \delta_{i-1}-\left|G^{*}\right| \sin \delta_{i}\right)\right]^{(\alpha / 1+\alpha)} \\
& \cdot\left(t_{i}-t_{i-1}\right)^{(1 / 1+\alpha)}
\end{aligned}
$$

where $I_{D}=$ the initial value of $\left|G^{*}\right|$ from the 1.0 percent applied strain interval, $\mathrm{MPa} ;\left|G^{*}\right|=$ the complex shear modulus, $\mathrm{MPa} ; \gamma_{0}=$ the applied strain, $\% ; \alpha=1 / m$, where $m=$ the slope of the logarithmic plot of the storage modulus versus the applied frequency; $t=$ the testing time, $s$;

The relationship between $\left|G^{*}\right| \sin \delta$ and $D(t)$ can be fitted using the equation (6):

$$
\left|G^{*}\right| \sin \delta=C_{0}-C_{1}(D)^{C_{2}}
$$

where $C_{0}=$ the average value of $\left|G^{*}\right| \sin \delta$ from the 0.1 percent strain interval; $C_{1}$ and $C_{2}=$ the coefficients of the curve fitting equations.

The damage failure $D_{\mathrm{f}}$ is defined as the value of $\mathrm{D}(t)$ that corresponds to a 35 percent reduction in undamaged $\left|G^{*}\right| \sin \delta\left(C_{0}\right)$.

$$
\begin{aligned}
& D_{f}=0.35\left(\frac{C_{0}}{C_{1}}\right)^{\left(1 / C_{2}\right)}, \\
& A_{35}=\frac{f\left(D_{f}\right)^{k}}{k\left(\pi I_{D} C_{1} C_{2}\right)^{\alpha}},
\end{aligned}
$$

where $f=10 \mathrm{~Hz} ; k=1+\left(1-\mathrm{C}_{2}\right) \alpha ; B=-2 \alpha$. 


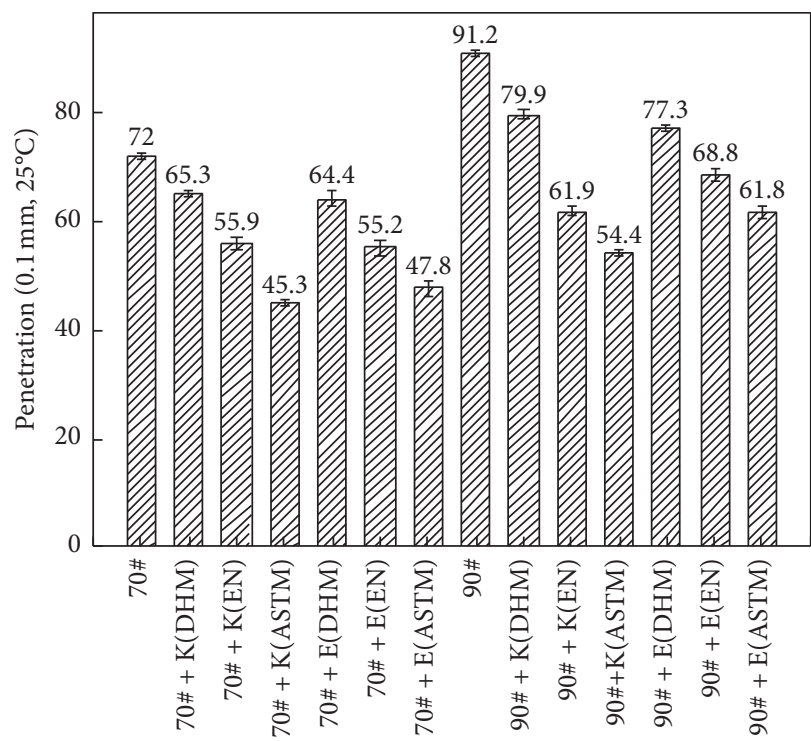

(a)

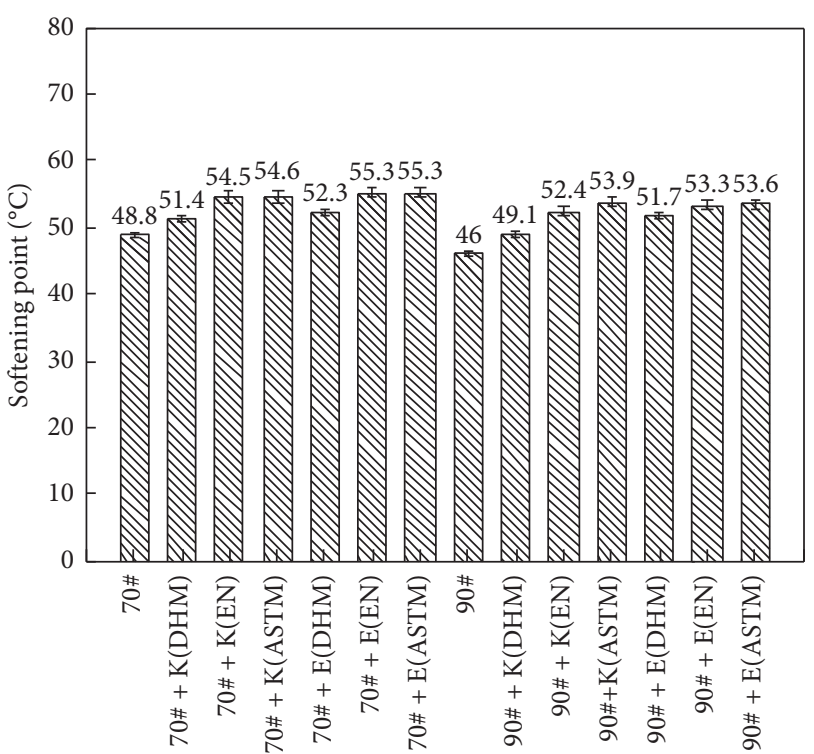

(b)

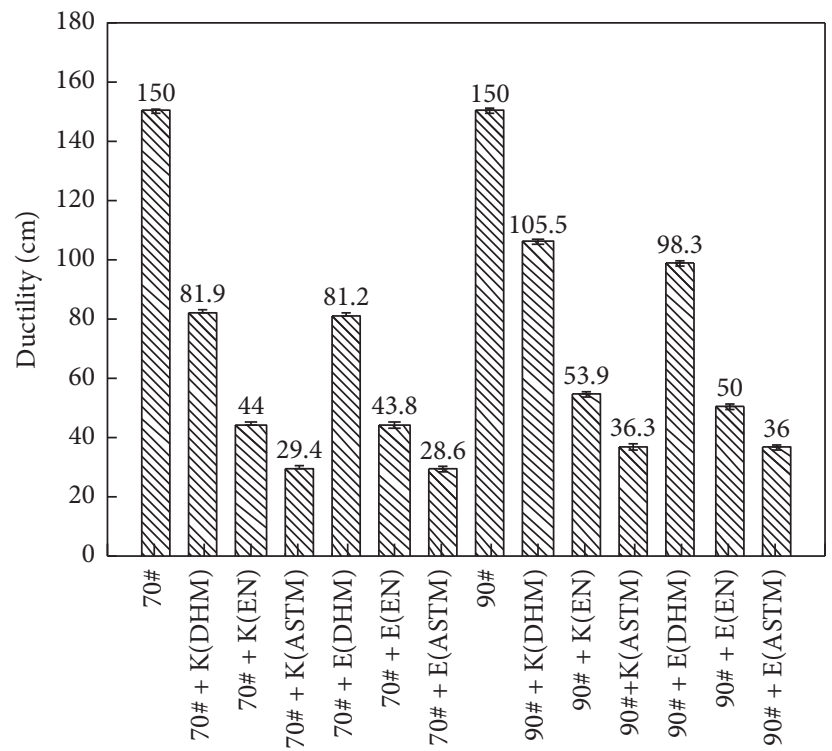

(c)

FIgUre 4: Performances of the emulsified asphalt residues.

$$
N_{f}=A_{35}\left(\gamma_{\max }\right)^{B}
$$

where $\gamma_{\max }=$ the maximum expected binder strain.

\section{Results and Discussion}

3.1. Physical Performance. The physical performance test results of the emulsified asphalt residues are shown in Figure 4. The ductility test values for the 70\# and 90\# matrix asphalt binders were greater than $150 \mathrm{~cm}$ and were recorded as $150 \mathrm{~cm}$. As can be seen from Figure 4, the evaporation method has significant effects on the penetration and the ductility of the residue but has little effect on the softening point. The penetration and ductility of the residues that were obtained by the direct heating method are the largest, followed by those obtained by the EN13074 evaporation method, and those obtained by the ASTM D7497-09 evaporation method are the smallest. The softening point of the residues that were obtained by the ASTM D7497-09 evaporation method is slightly higher than that obtained by the EN13074 evaporation method, and the values for the residues that were obtained by both evaporation methods are higher than that by the direct heating method. In addition, compared with the matrix asphalt, the softening point of emulsified asphalt residues increases and the ductility substantially decreases. The main reason is that the hydrophilic group of the emulsifier is mainly an amine group, and the amine group has a strong affinity with 


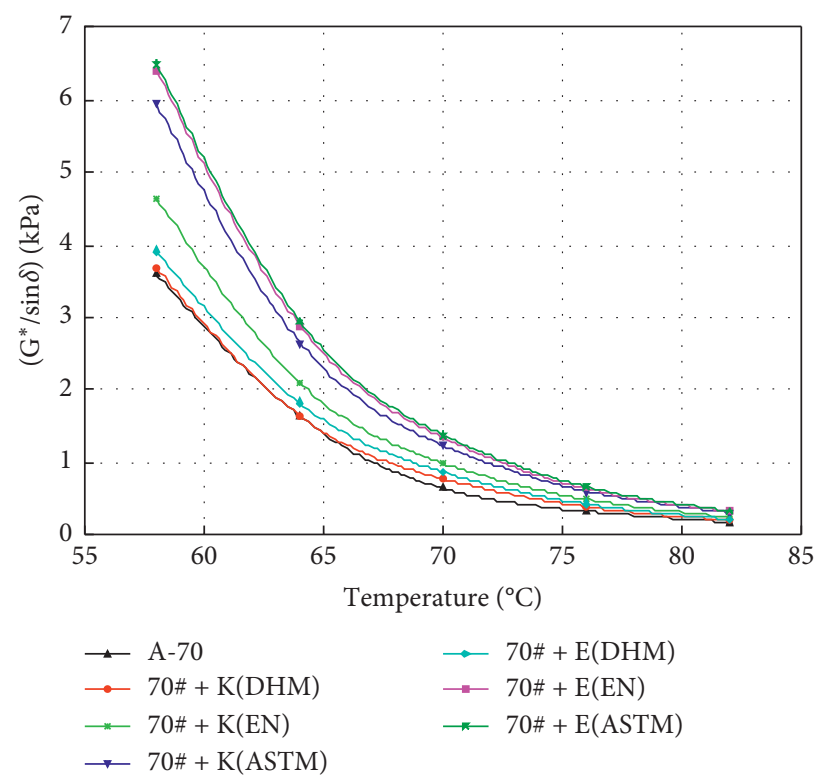

(a)

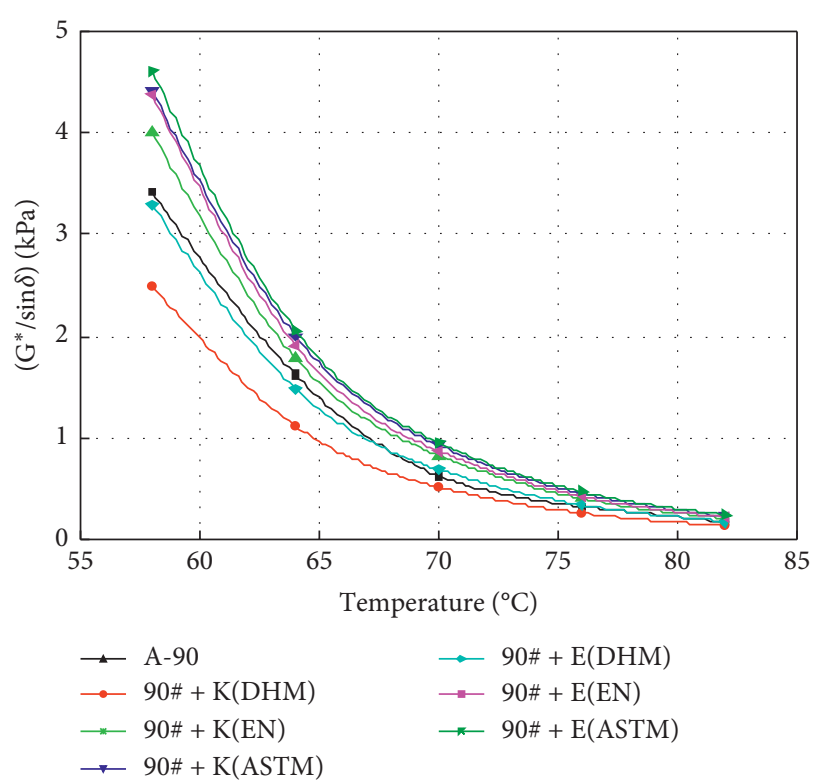

(b)

FIgURE 5: Variation of the rutting factor of the emulsified asphalt residue with temperature.

asphalt. When the content of the amine group reaches a certain amount, it will agglomerate the fusion between asphalt molecules and improve the performance of asphalt.

\subsection{Linear Viscoelasticity of the Emulsified Asphalt Residue}

3.2.1. Temperature Sweep Test Results. The rutting factor $\left(\mathrm{G}^{*} / \sin \delta\right)$ was used as an index to characterize the high performance of asphalt in AASHTO M320-05 [38]. The values of $\mathrm{G}^{*} / \sin \delta$ of the emulsified asphalt residues that were obtained via the different evaporation methods were used to analyze the high-temperature performance, as shown in Figure 5. The rutting factors of the residues decrease gradually with the increase in temperature. Hence, the rutting resistance decreases with the increase in the temperature. According to Figure 5(a), under the same temperature, the rutting factors of the $70 \#+\mathrm{K}$ emulsified asphalt residues that were prepared by the ASTM D7497-09 evaporation method are the largest, followed by that prepared by the EN13074 evaporation method, and the rutting factors of the residues that were obtained by the direct heating method are the smallest. The 70\#+E emulsified asphalt residues that were prepared by the ASTM D7497-09 and EN13074 evaporation methods have approximately the same rutting factors, which are significantly higher than those obtained by the direct heating method. According to Figure 5(b), the evaporation methods are ordered according the rutting factor of each residue as ASTM D749709>EN13074>DHM. The test results indicate that the oxidation of the binder during the residue recovery procedure could lead to a stiffer and more elastic response, and the results of Hanz et al. [39] and Islam et al. [19] confirmed this conclusion. Comparing Figures 5(a) and 5(b), the rutting factor of the 90\# asphalt binder is less than that of the 70\# asphalt binder, and the rutting factor of the emulsified asphalt residue that was prepared from the 90\# asphalt is less than that of the residue that was prepared from the 70\# asphalt. The results show that the matrix asphalt significantly affects the properties of the emulsified asphalt residue.

\subsubsection{Complex Modulus and Phage Angle Master Curves.}

The complex modulus and the phase angle master curves that correspond to the residues that were recovered using the three methods are plotted in Figure 6. At lower frequencies, these curves show that the complex modulus values of the residues that were prepared by both the ASTM D7497-09 and EN13074 evaporation methods are larger than those that were prepared by the direct heating method. The results show that the ASTM D7497-09 and EN13074-cured residues were stiffer than the direct-heating-method-cured residues for all emulsified asphalt binders. However, at high frequencies, the emulsified asphalt residues under different evaporation conditions have similar complex modulus values. Meanwhile, these curves also show that both the ASTM D7497-09 and EN13074-cured residues have smaller phage angles than the direct-heating-method-cured residues for all emulsified asphalt binders. Specifically, the ASTM D7497-09 and EN13074-cured residues have similar phage angle values for the $70 \#+E, 90 \#+K$, and $90 \#+E$ emulsified asphalt binders, while the $70 \#+\mathrm{K}$ emulsified asphalt shows significantly smaller phage angle values of the ASTM D749709-cured residues. The influences of the evaporation method on the complex modulus and the phase angle of residues differ, which has a strong relationship with the emulsifier type. Comparing Figure 6(a) with Figure 6(c), the slope for the emulsified asphalt residues prepared from 70\# asphalt is greater than that for the residues prepared from 90\# asphalt. Therefore, the emulsified asphalt residues that were prepared 


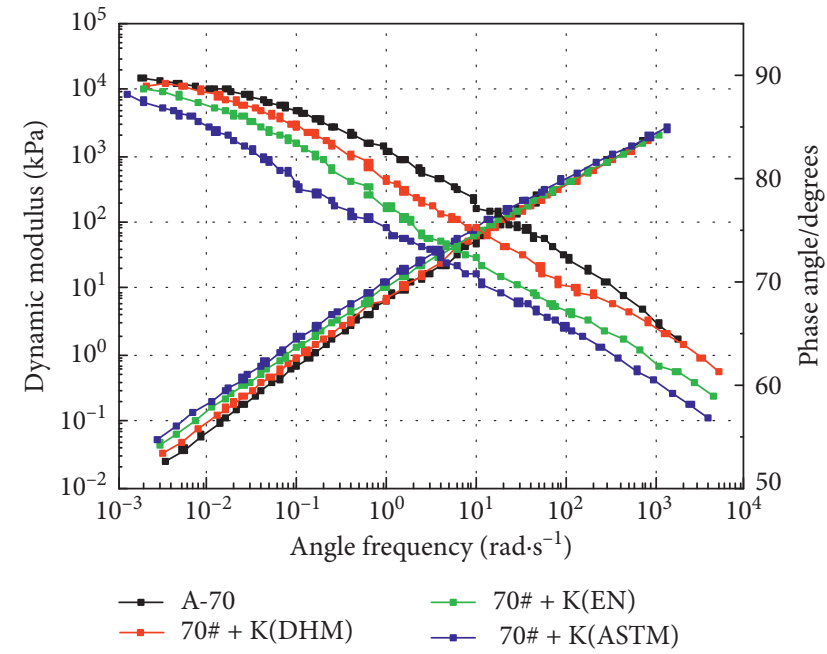

(a)

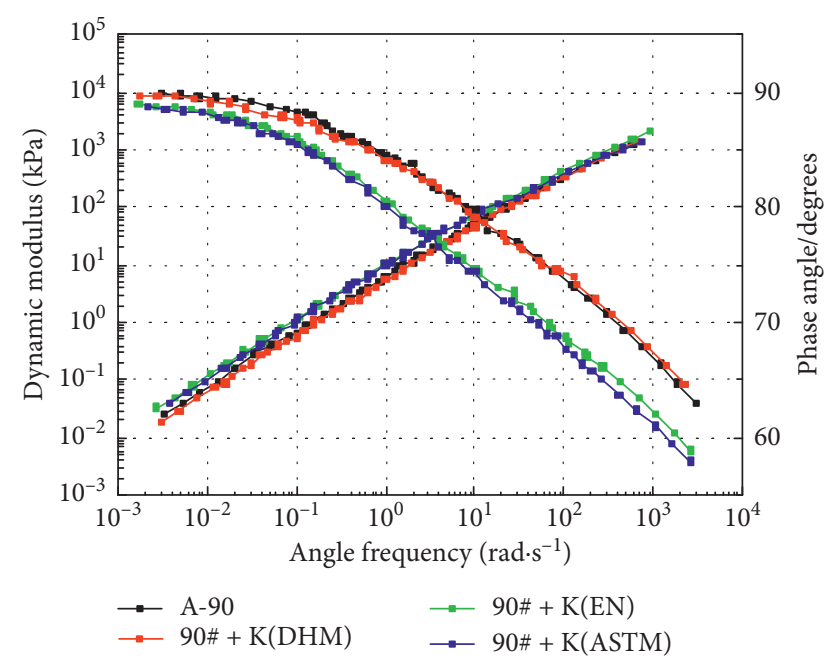

(c)

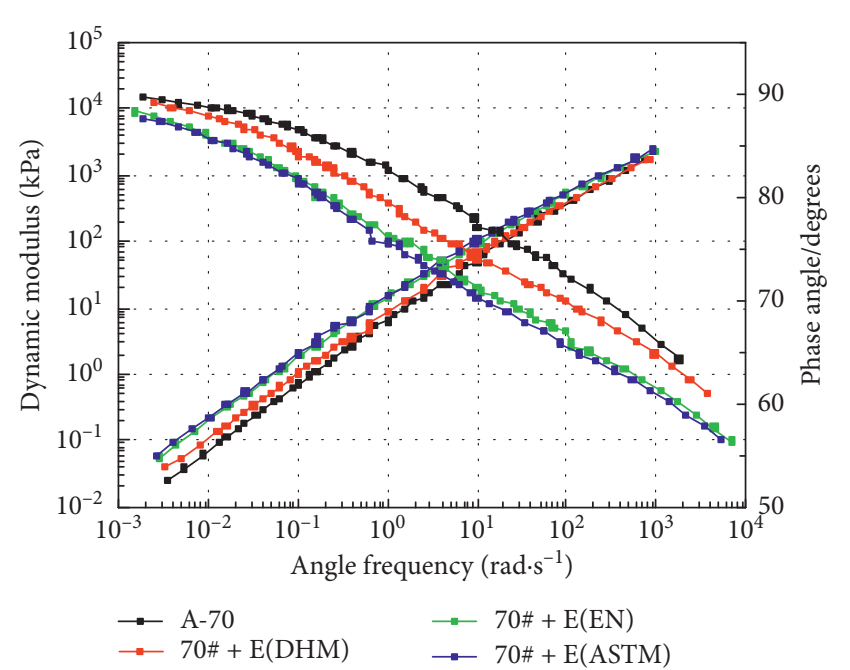

(b)

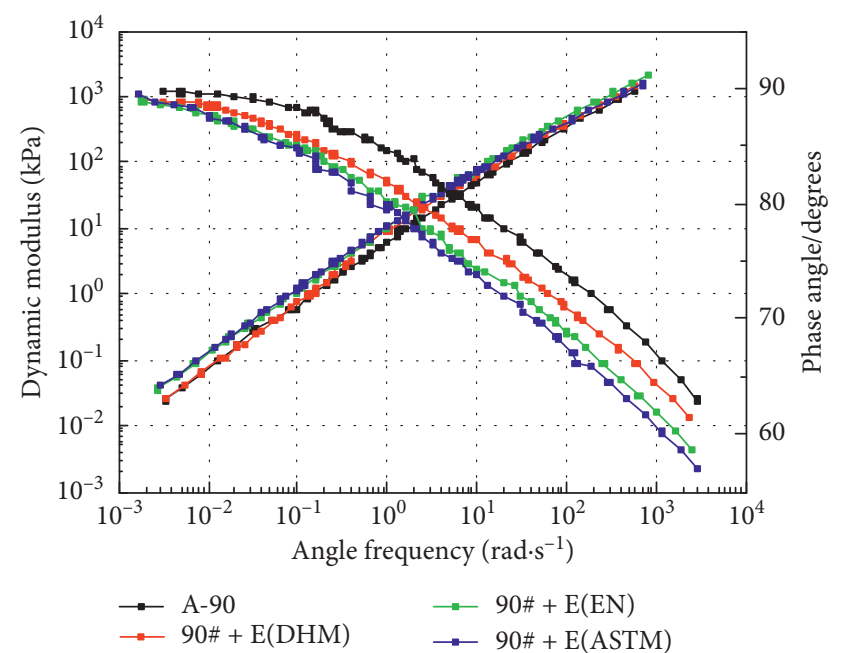

(d)

Figure 6: Master curves of emulsified asphalt residues at a reference temperature of $40^{\circ} \mathrm{C}$.

from 70\# asphalt are more susceptible to temperature changes than the emulsified asphalt residues that were prepared from $90 \#$ asphalt.

\subsection{Permanent Deformation Resistance}

3.3.1. Analysis of the Nonrecoverable Compliance and the Percent Recovery. The calculated performance indicators, namely, the nonrecoverable creep compliance $\left(J_{\mathrm{nr}}\right)$ and the recovery percent $(R)$ are summarized in Figures 7 and 8 . For all emulsified asphalt binders, the $J_{\mathrm{nr}}$ values of the emulsified asphalt residues that were prepared by the direct heating method are significantly higher than those of the residues that were prepared by the EN13074 and ASTM D7497-09 evaporation methods. Moreover, the $J_{\mathrm{nr}}$ values of the emulsified asphalt residues that were prepared by the ASTM D7497-09 evaporation method are the smallest. At $64^{\circ} \mathrm{C}$ and $70^{\circ} \mathrm{C}$, except for $90 \#+\mathrm{K}(\mathrm{DHM})$, the $J_{\mathrm{nr}}$ values of the emulsified asphalt residues were found to be smaller than those of the matrix binders. Hence, the addition of emulsifiers can improve the permanent deformation resistance of the emulsified asphalt. As shown in Figure 7, the $J_{\mathrm{nr}}$ values of the emulsified asphalt residues that were prepared from 90\# asphalt are greater than those of the emulsified asphalt residues that were prepared from 70\# asphalt, and the higher the temperature is, the larger the $J_{\mathrm{nr}}$ values of the emulsified asphalt residues are.

Figure 8 shows the values of the percent recovery of emulsified asphalt residues under different stresses and temperatures. The evaporation method significantly influenced the percent recovery of the emulsified asphalt residues, especially at the low stress level. Under three different evaporation conditions, all the emulsified asphalt residues show the same trend: R (ASTM D7497-09) > R (EN13074) $>\mathrm{R}$ (DHM). This is mainly because the emulsified asphalt residues were aged during the evaporation process, and the light components in the residues were converted into heavy components, which caused the emulsified asphalt residues to 


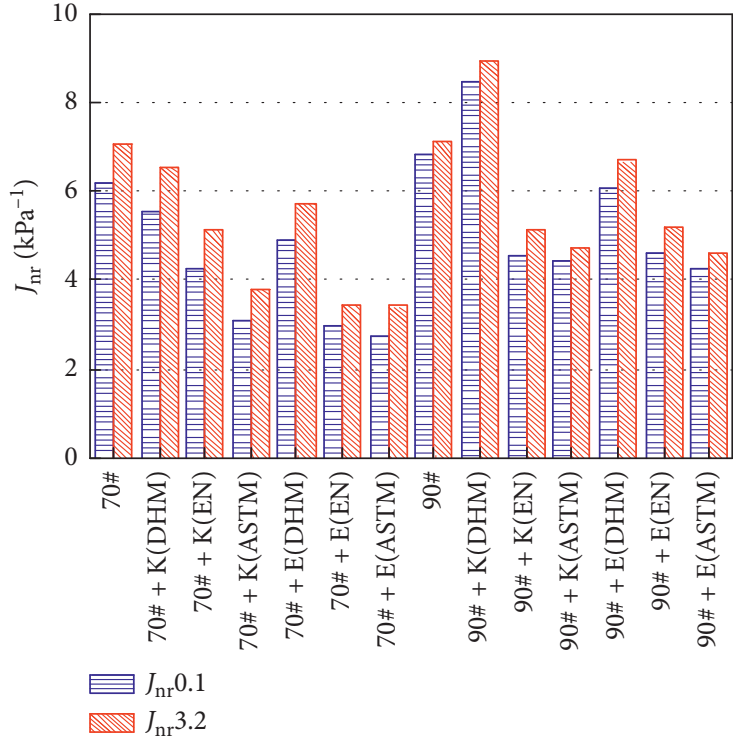

(a)

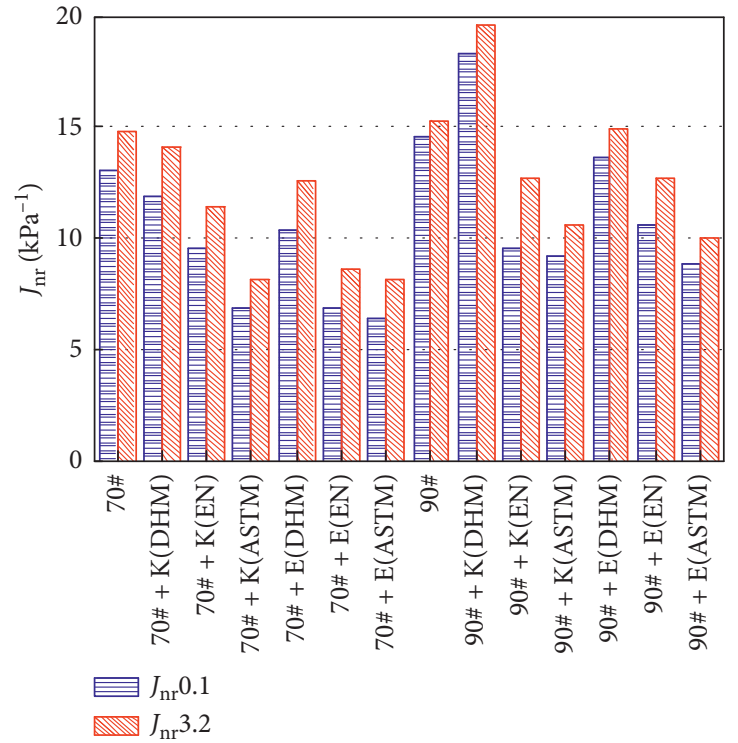

(b)

Figure 7: $J_{\mathrm{nr}}$ values for emulsified asphalt residues at (a) $64^{\circ} \mathrm{C}$ and (b) $70^{\circ} \mathrm{C}$.

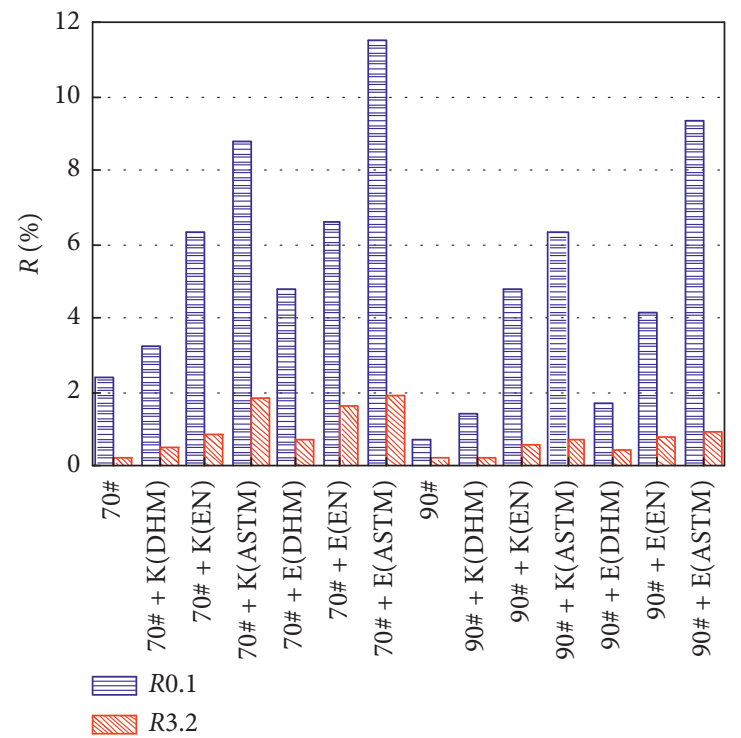

(a)

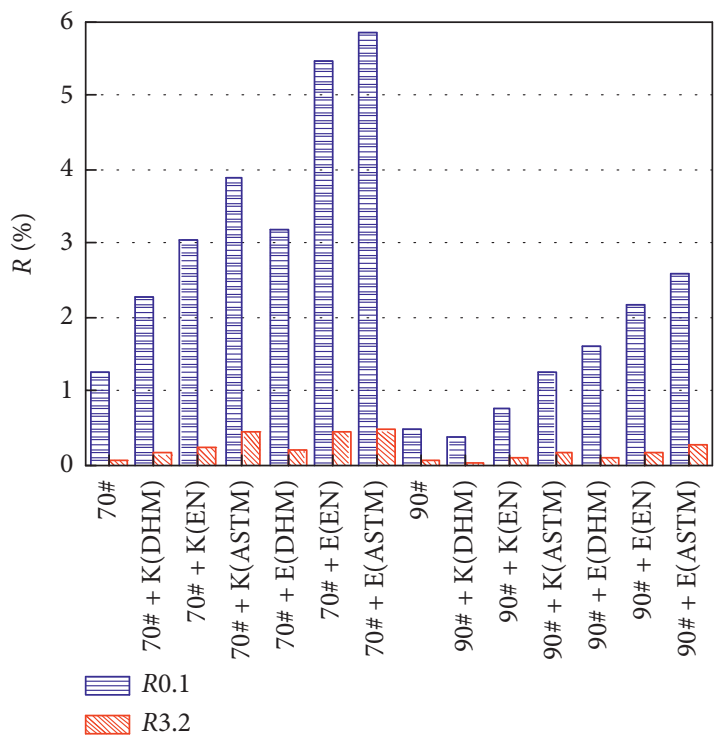

(b)

Figure 8: Percent recovery results for emulsion asphalt residues at (a) $64^{\circ} \mathrm{C}$ and (b) $70^{\circ} \mathrm{C}$.

harden and the deformation recovery ability to be enhanced. The matrix asphalt has a percent recovery of almost $0 \%$ at high stress, compared to approximately $1 \%$ at low stress. The addition of emulsifier improves the percent recovery of the matrix binder at both levels of stress, namely, $0.1 \mathrm{kPa}$ and $3.2 \mathrm{kPa}$. In addition, the recovery percentage values of the residues that were prepared from the $70 \#$ asphalt binder are greater than those of the emulsified asphalt residues that were prepared from the 90\# asphalt. From the overall MSCR results, together with the rutting factors from temperature sweep test, it is concluded that the presence of an emulsifier increases the rutting resistance and the high-temperature deformation resistance of the asphalt binder. Furthermore, the residues that were prepared from $70 \#$ asphalt have better high-temperature performance than the residues that were obtained from 90\# asphalt.

3.3.2. Analysis of the Stress Sensitivity. Figure 9 presents the $J_{\mathrm{nr}}$, diff value results for emulsified asphalt residues at different testing temperatures. At $64^{\circ} \mathrm{C}$ and $70^{\circ} \mathrm{C}$, the $J_{\mathrm{nr} \text {, diff }}$ values of all binders were below $75 \%$. Except for $90 \#+\mathrm{K}$ (EN), the emulsified asphalt residues that were prepared from the 90\# asphalt have lower $J_{\mathrm{nr}}$, diff values than the 


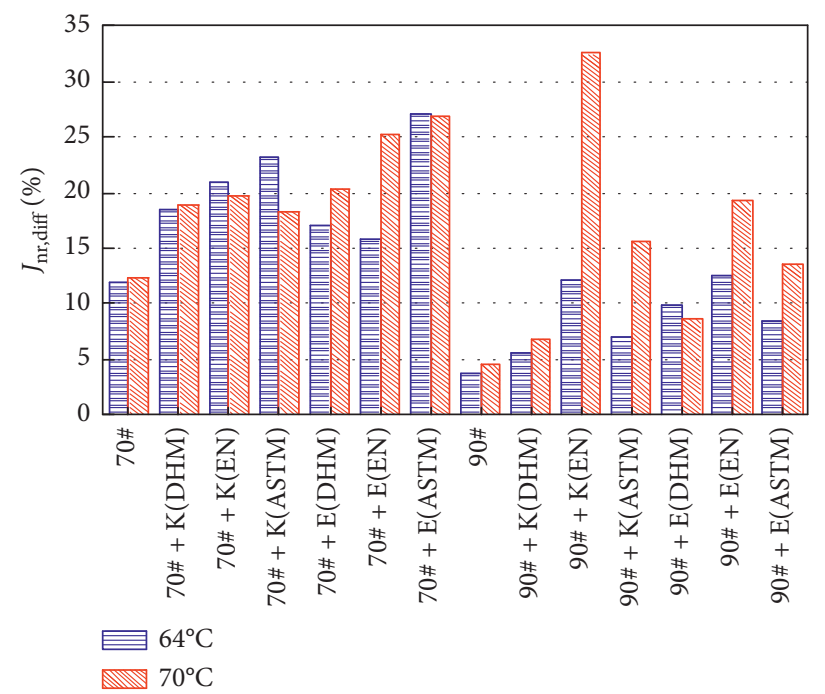

FIgURE 9: $J_{\mathrm{nr}}$, diff value results for the emulsified asphalt residues.

TABLE 3: VECD analysis parameter results of the LAS test for the emulsified asphalt residues.

\begin{tabular}{|c|c|c|c|c|c|c|c|c|}
\hline Binder type & $C_{0}$ & $C_{1}$ & $C_{2}$ & $A$ & $B$ & $\alpha$ & $\tau_{\max }(\mathrm{kPa})$ & $R^{2}$ \\
\hline $70 \#$ & 1.757 & 0.048 & 0.559 & 213069 & -2.325 & 1.163 & 127 & 0.986 \\
\hline 70\#+K(DHM) & 1.246 & 0.026 & 0.633 & 302052 & -2.425 & 1.213 & 105 & 0.987 \\
\hline $70 \#+K(\mathrm{EN})$ & 1.508 & 0.152 & 0.370 & 419745 & -2.665 & 1.332 & 66 & 0.910 \\
\hline $70 \#+K($ ASTM $)$ & 1.958 & 0.314 & 0.285 & 565058 & -2.826 & 1.413 & 70 & 0.967 \\
\hline 70\#+E(DHM) & 0.448 & 0.041 & 0.520 & 481109 & -2.987 & 1.493 & 33 & 0.994 \\
\hline $70 \#+\mathrm{E}(\mathrm{EN})$ & 1.664 & 0.042 & 0.569 & 349896 & -2.505 & 1.253 & 132 & 0.992 \\
\hline 70\#+E(ASTM) & 0.679 & 0.041 & 0.534 & 494815 & -2.805 & 1.402 & 43 & 0.984 \\
\hline $90 \#$ & 1.556 & 0.045 & 0.570 & 145737 & -2.229 & 1.114 & 118 & 0.986 \\
\hline $90 \#+\mathrm{K}(\mathrm{DHM})$ & 1.304 & 0.022 & 0.670 & 175995 & -2.244 & 1.122 & 118 & 0.983 \\
\hline $90 \#+K(E N)$ & 1.505 & 0.045 & 0.554 & 300217 & -2.427 & 1.214 & 119 & 0.992 \\
\hline $90 \#+K($ ASTM $)$ & 1.598 & 0.044 & 0.557 & 457384 & -2.606 & 1.303 & 126 & 0.992 \\
\hline $90 \#+\mathrm{E}(\mathrm{DHM})$ & 2.217 & 0.057 & 0.563 & 198238 & -2.515 & 1.257 & 150 & 0.982 \\
\hline $90 \#+\mathrm{E}(\mathrm{EN})$ & 2.059 & 0.219 & 0.348 & 237099 & -2.510 & 1.255 & 78 & 0.961 \\
\hline $90 \#+\mathrm{E}(\mathrm{ASTM})$ & 1.674 & 0.031 & 0.620 & 228496 & -2.335 & 1.168 & 132 & 0.984 \\
\hline
\end{tabular}

emulsified asphalt residues that were prepared from $70 \#$ asphalt. When the emulsifier was added to the matrix asphalt binders, the $J_{\mathrm{nr}}$, diff values increased, namely, the inclusion of the emulsifier caused the emulsified asphalt to be more sensitive to stress. The evaporation method influenced the $J_{\mathrm{nr}}$, diff values of the emulsified asphalt residues, but the change trend is different. Specifically, for $70 \#+\mathrm{K}$ and $70 \#+\mathrm{E}$ emulsified asphalt, the residues obtained by the ASTM D7497-09 evaporation method have the largest $J_{\text {nr, diff }}$ values. For $90 \#+\mathrm{K}$ and $90 \#+\mathrm{E}$ emulsified asphalt, the residues obtained by the EN13074 evaporation method have the largest

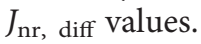

\subsection{Fatigue Resistance}

3.4.1. Analysis of the Damage Intensity and Integrity Parameters. The LAS test fatigue damage values for different emulsified asphalt residues are provided in Table 3. Lower values of $C_{1}$ and $C_{2}$ correspond to higher binder fatigue performance $[35,40,41]$. According to Table 3 , under the different evaporation methods, the values of parameters $C_{1}$ and $C_{2}$ have different trends, increasing or decreasing. It is difficult to judge the fatigue performance of the emulsified asphalt residues.

To clearly see the overall impact of the decrease in the integrity parameter, the fatigue damage should be evaluated in combination with the relationship between the damage intensity $(D)$ and the integrity parameter $(C)$, as presented in Figure 10. The value of $C$ is 1 , which means that the asphalt binder is not damaged, and the value of $C$ is 0 , which means that the asphalt binder is completely damaged. The test results demonstrate that the evaporation method influences the fatigue damage tolerance of the emulsified asphalt residue. According to Figure 10(a), at the specified damage level $(D)$, the residues prepared by the evaporation method of ASTM D7497-09 have the lowest integrity, followed by EN13074 evaporation, and the residues prepared by the direct heating method have the highest integrity. However, the emulsified asphalt residues that were prepared from 90\# asphalt show more complicated change trends under 


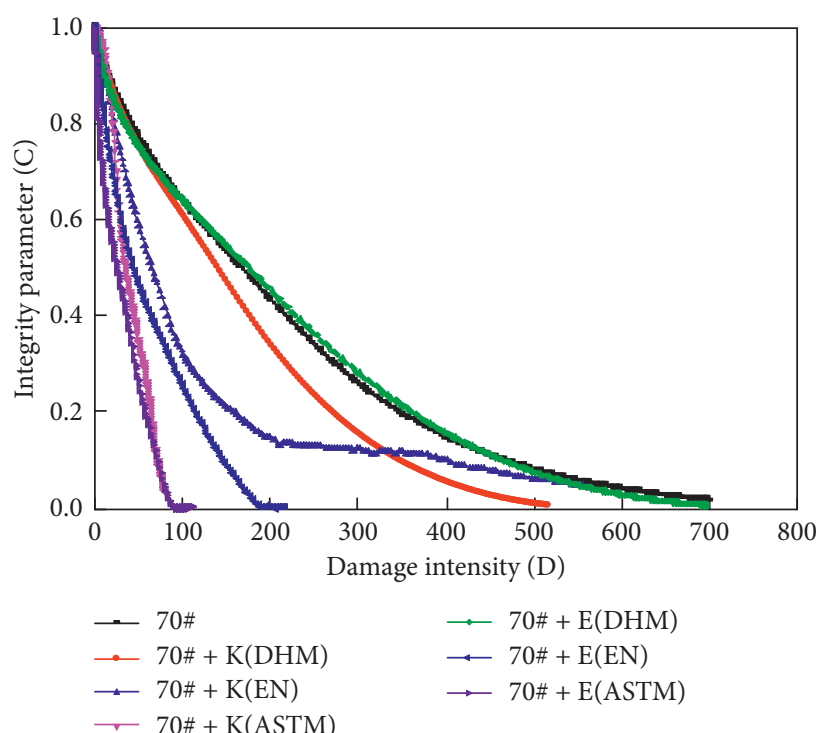

(a)

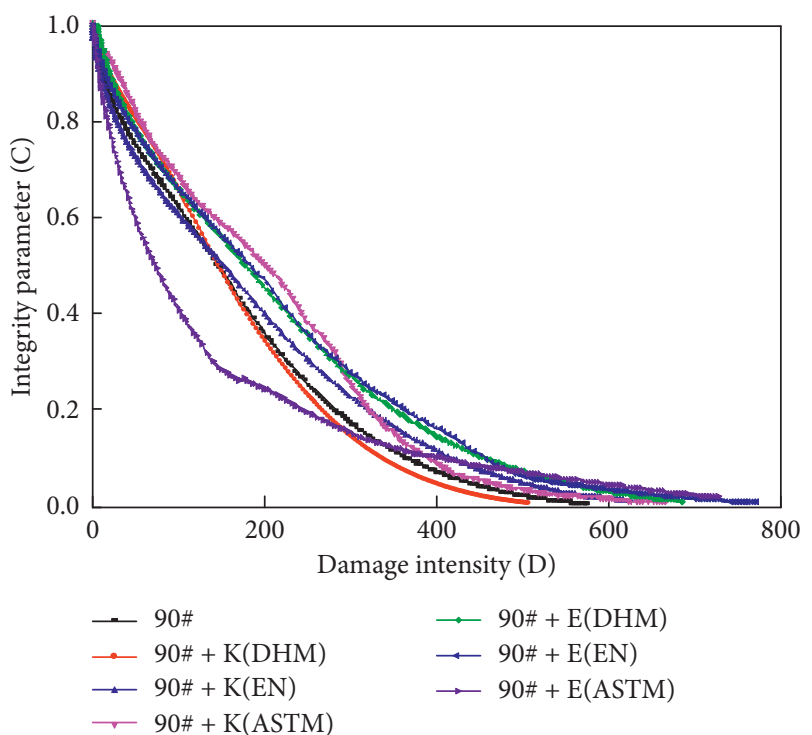

(b)

FIGURE 10: Integrity parameter versus damage intensity for the emulsified asphalt residues.

different evaporation methods. According to Figure 10(b), the evaporation methods are ordered in terms of the integrity of the $90 \#+\mathrm{K}$ emulsified asphalt residues as follows: $\mathrm{C}$ (ASTM D7497-09) $>$ C (EN13074) $>$ C (DHM). While the $90 \#+E$ emulsified asphalt residues that were prepared by EN13074 and the direct heating method have similar integrities, their integrities are significantly greater than those prepared by the ASTM D7497-09 evaporation method.

3.4.2. Analysis of the Number of Cycles to Fatigue Failure $\left(N_{f}\right)$. Figure 11 shows the number of cycles to fatigue failure in the LAS test for the emulsified asphalt residue at the 2.5\% strain level. The significant influences of the evaporation method and the emulsifier type on the fatigue performance are demonstrated via an analysis of variance that was conducted at a confidence level of $95 \%$, which identified the evaporation method and the emulsifier type as significant factors, and the average $p$ values are 0.000 and 0.009 , respectively. According to these data, although there are differences among the emulsions, the evaporation method had the most significant impact on the fatigue life. As shown in Figure 11, the three evaporation methods are ordered in terms of the fatigue life of the four emulsified asphalts as follows: $N_{\mathrm{f}}$ (ASTM D7497-09) $>N_{\mathrm{f}}\left(\right.$ EN13074) $>N_{\mathrm{f}}(\mathrm{DHM})$. In addition, the fatigue life of the $\mathrm{K}$ emulsified asphalt residues is greatly affected by the evaporation method. Under the different evaporation methods, the fatigue life change rate of the $\mathrm{K}$ emulsified asphalt is greater than that of the E emulsified asphalt residue. The change in the fatigue life is consistent with Hintz et al. [42], who reported that aging was beneficial to the fatigue performance at small strain amplitudes and detrimental at high stain amplitudes. Furthermore, the rate at which the material ages depend on the chemical properties of the emulsifier, and the variation in

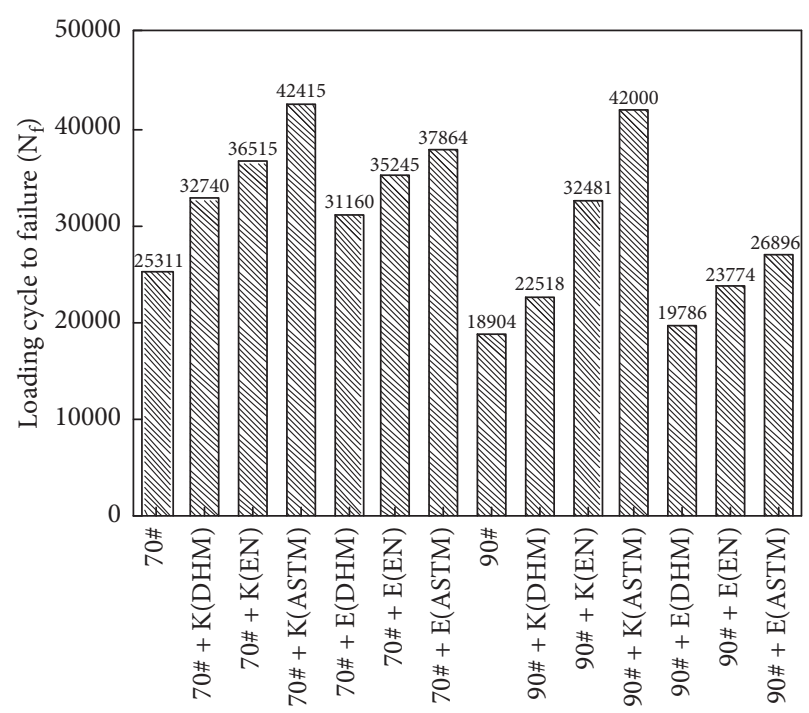

FIGURE 11: LAS test fatigue life of emulsified asphalt residues at the $2.5 \%$ strain level.

aging susceptibility is more prevalent in cationic emulsions [42].

To explain the oxidation phenomenon in terms of the binder chemistry, Ge et al. [14] and Malladi et al. [23] conducted a Fourier transform infrared spectroscopy (FTIR) test. Test results showed that compared with $\mathrm{S}=\mathrm{O}$ and $\mathrm{C}=\mathrm{O}$ of the emulsified asphalt residue can better characterize the aging of the emulsified asphalt. However, no clear trend was observed in the relative oxidation levels of the emulsion residues that were recovered using various evaporation methods. This problem remains unsolved, and many studies are being conducted to understand the curing procedure of emulsified asphalt residues. 


\section{Conclusions and Recommendations}

This study investigated the effects of evaporation methods on the rheological and fatigue performances of emulsified asphalt residues using physical tests, linear viscoelastic property tests, permanent deformation resistance tests, and fatigue resistance tests. The following conclusions are obtained:

(1) Under the three evaporation conditions, the penetration and ductility of residues obtained by the direct heating method are the largest, followed by those obtained by EN13074 evaporation method, and the penetration and ductility of residues obtained by the ASTM D7497-09 evaporation method are the smallest. However, the evaporation method has little effect on the softening point of emulsified asphalt residues.

(2) The growth amplitude order of the rutting factor and the recovery percent values of emulsified asphalt residues is ASTM D7497-09>EN13074>DHM, and as is the attenuation amplitude order by the nonrecoverable creep compliance. The overall results indicate that the residues obtained by ASTM D749709 suffered more serious aging than EN13074 and direct heating methods.

(3) Compared with the residues obtained by the direct heating method, the emulsified asphalt residues obtained by the EN13074 and ASTM D7497-09 evaporation method have higher complex modulus and exhibit lower phase angle values in terms of various frequencies.

(4) The results of the variance analysis prove that the evaporation method has more significant influence on the fatigue life of the residues. The three different evaporation methods are ordered according to the fatigue life as $N_{\mathrm{f}}$ (ASTM D7497-09) $>N_{\mathrm{f}}(\mathrm{EN} 13074)$ $>N_{\mathrm{f}}$ (DHM).

(5) The rheological and fatigue performances of the residues depend on the matrix asphalt. Compared with the emulsified asphalt residue that was prepared from 90\# asphalt, the residue that was prepared from 70\# asphalt has good high-temperature and fatigue properties, but it has higher temperature sensitivity and stress sensitivity.

This research provides an effective strategy for finding a method that most accurately reflects the residual binders that are applied in the field and promotes the application of emulsified asphalt. It is recommended that an investigation of the chemical and rheological properties of the residual binders that are recovered from the field should be conducted to identify the residue recovery procedure that best reflects the residual binder that is placed in the field.

\section{Data Availability}

The data used to support the findings of this study are included within the article.

\section{Conflicts of Interest}

The authors declare that there are no conflicts of interest regarding the publication of this paper.

\section{Acknowledgments}

This work was financially supported by the National Natural Science Foundation of China, China (grant no. 51708513), and the research project of Henan Provincial Department of Transportation, China (grant no. 2019 (J) 1). The authors are sincerely grateful for their support.

\section{References}

[1] J. Zhang, Z. Fan, D. Hu, Z. Hu, J. Pei, and W. Kong, "Evaluation of asphalt-aggregate interaction based on the rheological properties," International Journal of Pavement Engineering, vol. 19, no. 7, pp. 586-592, 2018.

[2] X. Sheng, M. Wang, T. Xu, and J. Chen, "Preparation, properties and modification mechanism of polyurethane modified emulsified asphalt," Construction and Building Materials, vol. 189, pp. 375-383, 2018.

[3] H. Taherkhani, F. Firoozei, and J. Bolouri Bazaz, "Evaluation of the mechanical properties of the cement treated cold-inplace recycled asphalt mixtures," International Journal of Transportation Engineering, vol. 3, no. 4, pp. 301-312, 2016.

[4] J. Xiao, W. Jiang, W. Ye, J. Shan, and Z. Wang, "Effect of cement and emulsified asphalt contents on the performance of cement-emulsified asphalt mixture," Construction and Building Materials, vol. 220, pp. 577-586, 2019.

[5] M. O. Marasteanu and T. R. Clyne, "Rheological characterization of asphalt emulsions residues," Journal of Materials in Civil Engineering, vol. 18, no. 3, pp. 398-407, 2006.

[6] S. Sanjeevan, M. Piratheepan, E. Y. Hajj, and A. K. Bush, "Cold in-place recycling in Nevada," Transportation Research Record: Journal of the Transportation Research Board, vol. 2456, no. 1, pp. 146-160, 2014.

[7] D. Salomon, M. Thompson, G. Durand et al., "Comparison of rheological properties for recovered residue from emulsified asphalt obtained by three recovery procedures," in Proceedings of the International Symposium of Asphalt Emulsion Technology (ISAET), Washington, DC, USA, September 2008.

[8] J. Y. Pang, S. J. Du, and R. T. Chang, "Effect of emulsifier content on the rheological properties of asphalt emulsion residues," Journal of Applied Polymer Science, vol. 132, no. 15, 2015.

[9] G. J. Xu, M. Z. Chen, S. P. Wu, M. Van De Ven, and S. Mookhoek, "Rheological characteristics of residue binder from low penetration grade bitumen emulsion," Key Engineering Materials, vol. 509, pp. 328-332, 2012.

[10] G. N. King, H. King, and L. Galehouse, "Field validation of performance-based polymer-modified emulsion residue tests: the FLH study," in Proceedings of the First International Conference on Pavement Preservation California Department of Transportation Federal Highway Administration Foundation for Pavement Preservation, pp. 247-267, Newport Beach, CA, USA, June 2010.

[11] A. Motamed, D. Salomon, N. Sakib, and A. Bhasin, "Emulsified asphalt residue recovery and characterization," Transportation Research Record: Journal of the Transportation Research Board, vol. 2444, no. 1, pp. 88-96, 2014. 
[12] D. G. Hazlett, "Emulsion residue recovery techniques: how do we get emulsion residue representative of in-service binder?" Journal of the Transportation Research Board, no. E-C122, 2007.

[13] J. C. Waters, G. M. Bosma, and P. R. Herrington, Residual Binder Extraction from Emulsions for Quality Assurance Testing, Vol. 360, New Zealand Transport Agency, Wellington, New Zealand, 2008.

[14] D. D. Ge, Z. P. You, and S. Y. Chen, "Residue performance evaluation of emulsified asphalt," in Proceedings of the 12th International Conference on Low-Volume Roads, pp. 2-7, Kalispell, MT, USA, September 2019.

[15] K. Takamura and C. Lubbers, "Comparison of emulsion residues recovered by forced airflow and RTFO drying," in Proceedings of the ISSA/AEMA Proceedings, pp. 1-17, Amelia Island, FL, USA, March 2000.

[16] M. J. Farrar, S. L. Salmans, and J.-P. Planche, "Recovery and laboratory testing of asphalt emulsion residue," Transportation Research Record: Journal of the Transportation Research Board, vol. 2370, no. 1, pp. 69-75, 2013.

[17] A. J. Hanz, P. Johannes, and H. U. Bahia, "Development of emulsion residue testing framework for improved chip seal performance," Transportation Research Record: Journal of the Transportation Research Board: Transportation Research Record, vol. 2293, no. 1, pp. 106-113, 2012.

[18] M. Hospodka, B. Hofko, and R. Blab, "Impact of distillation temperature on the solvent residue and viscoelastic properties of asphalt binders," Road Materials and Pavement Design, vol. 19, no. 6, pp. 1275-1287, 2018.

[19] R. M. Islam, S. S. Ashani, N. M. Wasiuddin, and W. B. King, "Effects of curing time, temperature, and vacuum pressure on asphalt emulsion residue recovered by vacuum drying method," Journal of Testing and Evaluation, vol. 43, no. 5, pp. 1134-1145, 2014.

[20] JTG E20-2011, Standard Test Methods of Bitumen and Bituminous Mixtures for Highway Engineering, China communications Press, Beijing, China, 2011.

[21] Q. Zhang, P. W. Hao, and Z. Y. Bai, "Research on effect of waterborne epoxy resin on modified asphalt emulsion and its mechanism," Highway Engineering, vol. 41, no. 2, pp. 109-112, 2016.

[22] X. W. Gao and J. Y. Pang, "Emulsified asphalt cold recycled mixture based on rheological properties," Journal of Chang'an University (Natural Science Edition), vol. 38, no. 4, pp. 21-28, 2018.

[23] H. Malladi, M. Asnake, A. LaCroix, and C. Castorena, "Lowtemperature vacuum drying procedure for rapid asphalt emulsion residue recovery," Transportation Research Record: Journal of the Transportation Research Board, vol. 2672, no. 28, pp. 256-265, 2018.

[24] C. Wang, W. Xie, Y. Chen, A. Diab, and Z. You, "Refining the calculation method for fatigue failure criterion of asphalt binder from linear amplitude sweep test," Journal of Materials in Civil Engineering, vol. 30, no. 2, Article ID 04017286, 2018.

[25] X. Hou, F. Xiao, R. Guo, Q. Xiang, T. Wang, and J. Wang, "Application of spectrophotometry on detecting asphalt content of emulsified asphalt," Journal of Cleaner Production, vol. 215, pp. 626-633, 2019.

[26] M. R. Mitchell, R. E. Link, and N. Prapaitrakul, "Comparative study on recovered binder properties using three asphalt emulsion recovery methods," Journal of Testing and Evaluation, vol. 38, no. 6, pp. 653-659, 2010.

[27] ASTM D, Standard Test Method for Penetration of Bituminous Materials, American Society for Testing and Materials, West Conshohocken, PA, USA, 2013.
[28] ASTM D, Standard Test Method for Softening Point of Bitumen (Ring-and-ball Apparatus), American Society for Testing and Materials, West Conshohocken, PA, USA, 2014.

[29] ASTM D, Standard Test Method for Ductility of Asphalt Materials, American Society for Testing and Materials, West Conshohocken, PA, USA, 2017.

[30] AASHTO Designation: T 315-06, Standard Test Method for Determining the Rheological Properties of Asphalt Binder Using a Dynamic Shear Rheometer (DSR), American Society for Testing and Materials, West Conshohocken, PA, USA, 2006.

[31] M. Marateanu and D. Anderson, "Time-temperature dependency of asphalt binders-an improved model (with discussion)," Journal of the Association of Asphalt Paving Technologists, vol. 65, 1996.

[32] M. L. Williams, R. F. Landel, and J. D. Ferry, "The temperature dependence of relaxation mechanisms in amorphous polymers and other glass-forming liquids," Journal of the American Chemical Society, vol. 77, no. 14, pp. 3701-3707, 1955.

[33] AASHTO Designation: TP 70-10, Standard Method of Test for Multiple Stress Creep Recovery (MSCR) Test of Asphalt Binder Using a Dynamic Shear Rheometer (DSR), American Society for Testing and Materials, West Conshohocken, PA, USA, 2010.

[34] X. Yang and Z. You, "High temperature performance evaluation of bio-oil modified asphalt binders using the DSR and MSCR tests," Construction and Building Materials, vol. 76, pp. 380-387, 2015.

[35] C. Hintz and H. Bahia, "Simplification of linear amplitude sweep test and specification parameter," Transportation Research Record: Journal of the Transportation Research Board, vol. 2370, no. 1, pp. 10-16, 2013.

[36] G. Xu, H. Wang, and H. Zhu, "Rheological properties and anti-aging performance of asphalt binder modified with wood lignin," Construction and Building Materials, vol. 151, pp. 801-808, 2017.

[37] AASHTO TP 101, Estimating Damage Tolerance of Asphalt Binders Using the Linear Amplitude Sweep, American Association of State Highway and Transportation Officials, Washington, DC, USA, 2014.

[38] AASHTO M. 320-05, Standard Specification for PerformanceGraded Asphalt Binder, American Society for Testing and Materials, West Conshohocken, PA, USA, 2005.

[39] A. J. Hanz, Z. A. Arega, and H. U. Bahia, "Rheological behavior of emulsion residues produced by evaporative recovery method," Transportation Research Record: Journal of the Transportation Research Board, vol. 2179, no. 1, pp. 102-108, 2010.

[40] R. Micaelo, A. Pereira, L. Quaresma, and M. T. Cidade, "Fatigue resistance of asphalt binders: assessment of the analysis methods in strain-controlled tests," Construction and Building Materials, vol. 98, pp. 703-712, 2015.

[41] C. Hintz, R. Velasquez, C. Johnson, and H. Bahia, "Modification and validation of linear amplitude sweep test for binder fatigue specification," Transportation Research Record: Journal of the Transportation Research Board, vol. 2207, no. 1, pp. 99-106, 2011.

[42] C. Hintz, R. Velasquez, and Z. Li, "Effect of oxidative aging on binder fatigue performance," Journal of the Association of Asphalt Paving Technologists, vol. 80, pp. 527-548, 2011. 